\title{
Senegaleses no Brasil: aspectos culturais, socioeconômicos e linguísticos
}

\author{
Senegaleses en Brasil: aspectos culturales, socioeconómicos e linguísticos
}

Senegalese in Brazil: cultural, socioeconomic and linguistics aspects

\author{
Thalena Evangelista Santos ${ }^{1}$ \\ Mirian Rose Brum-de-Paula ${ }^{2}$
}

\begin{abstract}
Resumo
Nos últimos anos, o fluxo migratório apresentou um aumento significativo no Brasil, recebendo imigrantes oriundos do seu próprio continente e de outros também, sobretudo da África e Ásia. Oriundos de países como Haiti, Senegal, Síria, Angola, Gana, entre outras nações, os imigrantes procuram, devido às condições socioeconômicas de seus países de origem, oportunidades que não encontram nesses territórios. Tendo em vista esse movimento imigratório, esse trabalho tem por objetivo, além de contextualizar aspectos socioculturais e socioeconômicos que envolvem esse deslocamento, desenvolver uma análise acerca de aspectos linguísticos, advindos do processo de aquisição do português brasileiro por senegaleses, com foco em dificuldades na produção de alguns sons do português. Percebe-se a intensa presença de imigrantes africanos no Brasil, sobretudo na região Sul do país. Na maioria das vezes, exercem atividades de pequeno comércio em cidades de grande e médio porte como, por exemplo, a venda de relógios, bijuterias ou roupas. Muitos imigrantes também são atraídos por oportunidades laborais ligadas a tradições religiosas e relacionadas a métodos de trabalho que seguem regras peculiares, como o abate halal, característico da tradição islâmica. Dessa maneira, os senegaleses, por serem muçulmanos, são contratados por indústrias alimentícias, pois apresentam os atributos e os conhecimentos necessários para realizar tal atividade. Enfim, além de explorar situações relacionadas à trajetória desses sujeitos, suas aspirações e adaptação no território brasileiro, a presente proposta inclui colocar em evidência o modo como os imigrantes senegaleses, vindos de um país rico linguisticamente, adquirem o português brasileiro.
\end{abstract}

Palavras-chave: aquisição; consoantes fricativas; imigração; língua estrangeira; senegaleses.

\section{Resumen}

En los últimos años, el flujo de migración ha aumentado significativamente en Brasil, recibiendo inmigrantes de su propio continente y de otros, especialmente de África y Asia. Provenientes de países como Haití, Senegal, Siria, Angola, Ghana, entre otras naciones, los inmigrantes buscan, debido a las condiciones socioeconómicas de sus países de origen, oportunidades que no se encuentran en estos territorios. En vista de este movimiento de inmigración, este trabajo tiene como objetivo, además de contextualizar los aspectos socioculturales y socioeconómicos que implican este desplazamiento, desarrollar un análisis de los aspectos lingüísticos derivados del proceso de adquisición del portugués brasileño por parte de los senegaleses, enfocándose en las dificultades de producción en algunos sonidos del portugués. Se nota la intensa presencia de inmigrantes africanos en Brasil, especialmente en la región sur del país. La mayoría de las veces, se dedican a actividades de pequeñas empresas en ciudades grandes y medianas, como la venta de relojes, bisutería o ropa. Muchos inmigrantes también se sienten atraídos por las oportunidades laborales vinculadas a las tradiciones religiosas y los métodos de trabajo que siguen reglas peculiares, como la matanza halal, característica de la tradición islámica. Por lo tanto, los senegaleses, que son musulmanes, son contratados por las industrias alimentarias, ya que tienen los atributos y el

\footnotetext{
${ }^{1}$ Mestranda em Linguagem, Texto e Imagem; Universidade Federal de Pelotas - UFPel; Pelotas, Rio Grande do Sul; Brasil; thalena_x3@hotmail.com

${ }^{2}$ Doutora em Ciências da Linguagem; Universidade Federal de Pelotas - UFPel; Pelotas, Rio Grande do Sul; Brasil; brumdepaula@yahoo.fr
} 
conocimiento necesarios para realizar dicha actividad. Finalmente, además de explorar situaciones relacionadas con la trayectoria de estos sujetos, sus aspiraciones y adaptación en el territorio brasileño, esta propuesta incluye destacar la forma en que los inmigrantes senegaleses, provenientes de un país lingüísticamente rico, adquieren portugués brasileño.

Palabras claves: adquisición; consonantes fricativas; inmigración; lengua extranjera; senegaleses.

\begin{abstract}
In recent years, migratory flow presents a significant increase in Brazil, receiving immigrants from all continents, principally from Africa and Asia. They are from countries like Haiti, Senegal, Syria, Angola, Ghana, among other nations, immigrants search for opportunities they did not have in their crountries, due to their socioeconomic conditions. In view of this migratory flow, the objective of this paper is developp an analysis about linguistics aspects that involves the acquisition language process of the Brazilian Portuguese by Senegalese, focused on production difficulties related to some sounds of Brazilian Portuguese, besides contextualizing sociocultural and socioeconomic aspects related to this displacement. There is an intense presence of Africans immigrants, principally in the South of Brazil. In most cases, they work doing small trade activities in big and midsize towns, selling watches, jewelry and clothes. A lot of immigrants arrived in Brazil searching for jobs relateds to religious traditions and realated to work method that presents peculiar rules, for example, halal slaughter, from Islamic tradition. For this reason, Senegalese are hired by food industries because they are Muslim and they have knowledge to do this activity. Therefore, besides exploring situations related to Senegalses immigrants trajectory, their aspirations and adaptation in Brazil, this paper aims to show the way how Senegaleses immigrants, from a country linguistically rich, acquire Brazilian Portuguese language.
\end{abstract}

Keywords: acquisition; foreign language, fricative consonants; immigration; Senegalese.

\title{
1. Introdução
}

Este trabalho é um recorte de uma pesquisa mais abrangente sobre os imigrantes advindos do Senegal, que se encontram no sul do Brasil. A pesquisa concerne, principalmente, a aspectos socioeconômicos e linguísticos dessa população. O presente artigo possui as seguintes seções: uma introdução, uma segunda parte consagrada a aspectos geográficos, econômicos e linguísticos do Senegal, uma terceira seção sobre os senegaleses instalados no Rio Grande do Sul, um quarto tópico concernente à aquisição do português brasileiro (PB) por esse grupo de imigrantes, seguido de mais duas partes: uma acerca de segmentos consonantais fricativos, de difícil aquisição para esses aprendizes do PB como língua adicional e outra contendo comparações entre o PB e o wolof, língua materna desses imigrantes. O artigo contém questões e hipóteses preliminares sobre as razões que motivam inadequações encontradas na produção de fricativas alveolares e alveopalatais do PB como língua adicional. Enfim, uma última parte diz respeito a considerações finais.

Desde o seu descobrimento, o Brasil tem sido o destino - forçado ou voluntário - de populações de distintas nações e continentes. Colonização, imigração e miscigenação são, consequentemente, processos que fazem parte da sua constituição. Os movimentos populacionais iniciais moldaram os traços dos habitantes do país, como tem revelado o 
projeto EPIGEN-Brasil (DATA). Ao longo do tempo, a dinâmica migratória se (re)desenhou, podendo ser explicada de formas diversas, o que envolve aspectos políticos, sociais e/ou econômicos. Oriundos de países como Venezuela, Haiti, Senegal, Gana ou Síria, dentre outras nações, motivados por fatores relacionados a aspectos socioeconômicos, à fuga de conflitos armados ou de perseguições políticas ou religiosas, atualmente, o Brasil representa a chance de um futuro melhor tanto para aqueles que se deslocam quanto para aqueles que ficam, uma vez que uma das aspirações que motivam o exílio é enviar ajuda para melhorar a qualidade de vida dos familiares que permanecem nas cidades ou vilarejos de origem.

A presença de imigrantes senegaleses na região Sul do Brasil é o foco deste trabalho. É possível encontrá-los realizando atividades comerciais como a venda de artigos de pequeno porte: relógios, bijuterias, meias, óculos de sol, fones de ouvido e outras mercadorias. Mas eles também exercem ofícios em outras áreas, atuando em marcenarias, postos de gasolina, restaurantes e na indústria alimentícia.

Algumas dessas indústrias seguem regras alimentares peculiares, ligadas a práticas culturais de cunho religioso. Para que essas indústrias possam exportar alimentos para países em que há o predomínio da tradição islâmica, por exemplo, é desejável a contratação de funcionários que conheçam o processo de criação e o abate halal, uma vez que devem ser efetuados por indivíduos que seguem os princípios do islã. Assim, para os imigrantes senegaleses, essa é uma oportunidade de ofício exequível, pois são muçulmanos e o desempenho dessas tarefas fazem parte de sua cultura.

O trabalho é fundamental para que os imigrantes possam sobreviver num país estrangeiro. Trata-se de uma conquista importante para que se integrem ao novo ambiente sociocultural. Mas a adaptação à sociedade que os acolhe depende também de uma integração linguística. Com efeito, a integração profissional está intimamente relacionada ao domínio da língua falada no país de acolhimento. Adquirir um novo idioma, no caso o português brasileiro (PB), é fundamental para que possam resolver problemas administrativos, de saúde ou de moradia, para que exponham suas competências e para que criem laços profissionais e de amizade. A aquisição do PB por imigrantes senegaleses é também um importante objetivo desta pesquisa.

Na próxima seção, destacam-se aspectos relativos ao país de origem desse grupo de imigrantes e às principais línguas empregadas no Senegal. 


\section{Senegal: aspectos geográficos, econômicos e linguísticos}

A República do Senegal, país localizado ao oeste do continente africano, apresenta uma população de aproximadamente 15 milhões de habitantes. O país faz fronteira com a Mauritânia, ao norte, o Mali, ao leste, a Guiné e a Guiné Bissau, ao sul e, embutido ao seu território, com a Gâmbia. É banhado pelo Oceano Atlântico, o que deve ter facilitado a chegada dos colonizadores durante o período colonial, o tráfico de escravos e a atual emigração de senegaleses em direção a destinações diversas (cf. Figura 1).

Embora o Senegal apresente abundância de recursos naturais e tenha a economia dinamizada pela agricultura, pela pesca, pelo turismo, pela construção e pela mineração (NDIAYA e LV, 2018), quase metade de sua população vive abaixo do nível de pobreza, de acordo com dados do The World Fact Book (2019). Segundo Gaillard e Lill (2013), o Senegal encontra-se na lista dos 50 países menos desenvolvidos do mundo. Na Figura 1, percebe-se que os sinais de desenvolvimento estão concentrados em pequenas áreas do seu território (principalmente nas regiões litorâneas, em tons de verde). As áreas mais vulneráveis -representadas pelos diferentes tons de laranja e pela cor bordô - prevalecem. A falta de oportunidades e a ausência de sinais de desenvolvimento estimulam o exílio de muitos de seus habitantes, principalmente, da população jovem.

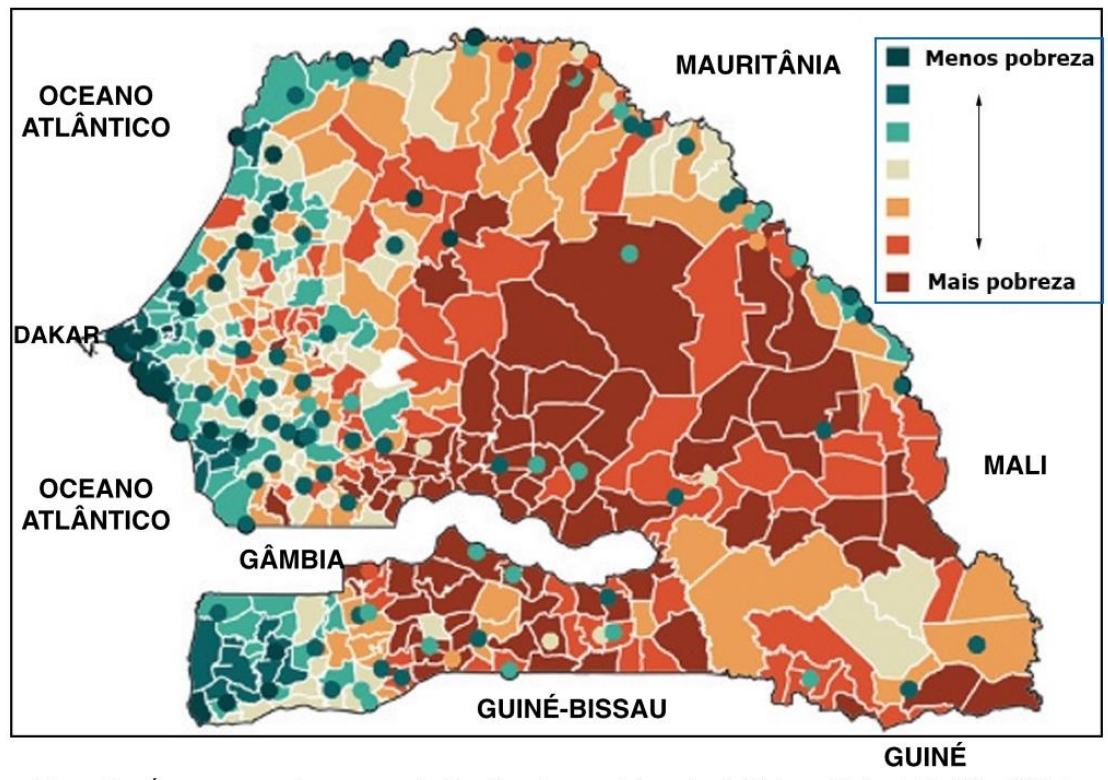

Figura 1 - Áreas com maior e menor índice de pobreza. Adaptado de Universidade de Buffalo (2017).

Land e Fourier (2012) destacam que, no Senegal, aproximadamente 70\% das famílias têm pelo menos um parente que migrou em busca de trabalho. Trata-se de deslocamentos internos e externos de uma população em constante movimento e contato interétnico. Ainda, 
como ocorre com africanos de outras nações, os senegaleses falam várias línguas, o que permite depreender que podem se adaptar mais facilmente a diferentes contextos culturais e linguísticos.

A África é, de fato, um continente linguisticamente rico, seus habitantes empregam mais de 800 línguas autóctones, além das línguas dos diferentes países que um dia a colonizaram e de várias línguas crioulas. Essa diversidade linguística é explicada, em parte, pelo encontro de três civilizações: a negro-africana, a arábico-islâmica e a ocidental. As línguas faladas no Senegal refletem essa origem multifacetada. Ligadas à primeira, encontram-se transmitidas e empregadas, por exemplo, as línguas pular, serer, diola, malinka, soninquê e, principalmente, o wolof, todas da família nigero-congolesa e reconhecidas como línguas nacionais do Senegal. Relacionada à segunda, destaca-se o uso, pela maior parte da população, que é islâmica, do árabe clássico, em situações cotidianas de culto religioso. No que diz respeito à terceira, identifica-se a língua francesa que, embora seja a língua oficial do Senegal, é principalmente empregada em Dakar, sendo língua materna de uma pequena elite que lá reside. Apesar de a língua francesa possuir o status de uma língua estrangeira, tende a evoluir em número de falantes, como pode-se observar no Gráfico 1:

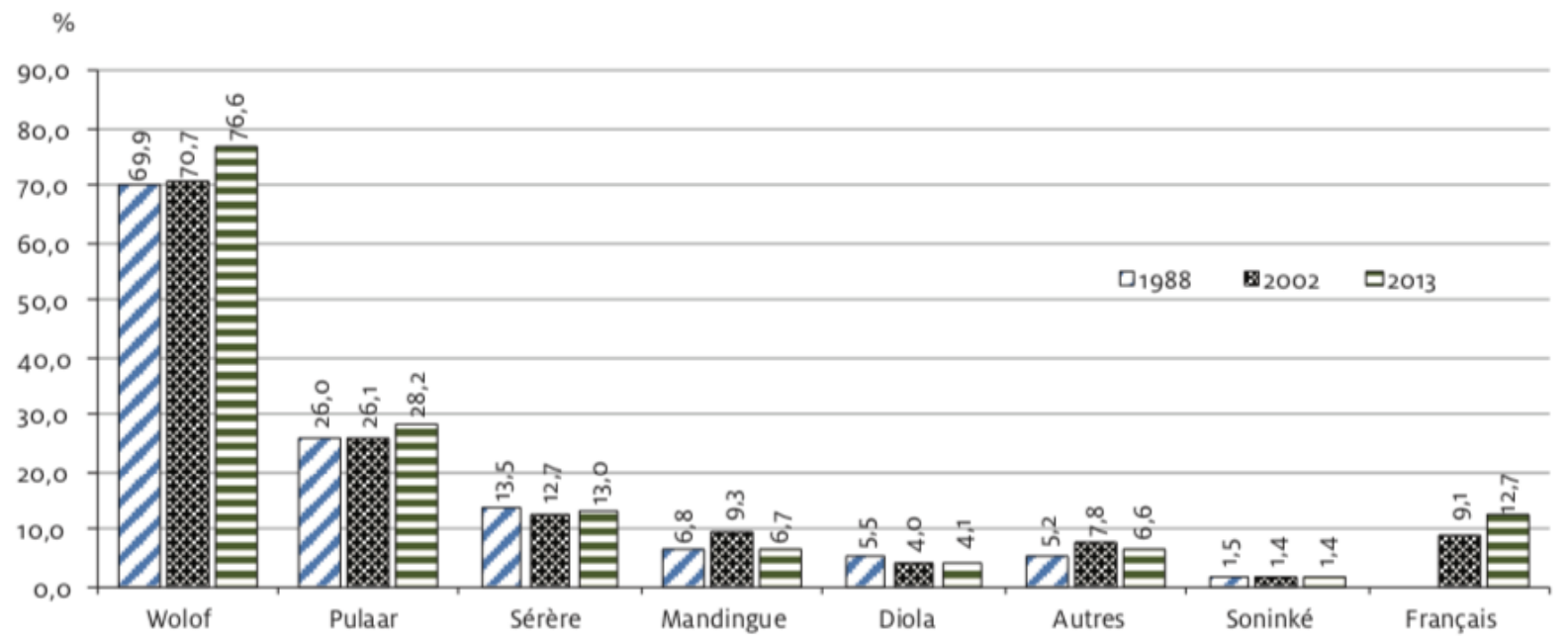

Gráfico 1 - Evolução dos locutores das principais línguas do Senegal

(DIOUF, NDIAYE e DIEME, 2017).

O Gráfico 1, que concerne ao aumento - ou ao decréscimo - dos falantes das principais línguas empregadas no Senegal, levando em conta um recorte que compreende os anos de 1988, 2002 e 2013, mostra, igualmente, a evolução do wolof, língua veicular do Senegal, e do pular, principalmente. Para Boubacar Diop, escritor senegalês, o wolof se desenvolve por conta do seu caráter "transétnico, que todo mundo fala ou compreende mais 
ou menos" (2019). Como pode ser observado, o wolof avança em relação às demais línguas nacionais, mas isso ocorre, principalmente, fora do sistema de ensino, sendo uma língua mais falada do que lida.

Na próxima seção, destacam-se características dos senegaleses que escolheram o sul do Brasil para emigrar.

\section{Senegaleses do Rio Grande do Sul}

Os imigrantes senegaleses que se encontram no estado do Rio Grande do Sul são, em sua maioria, do sexo masculino, apresentam faixa etária entre 19 e 50 anos (UEBEL, 2016) e vieram para o Brasil sozinhos ou acompanhados de amigos, sem trazer membros da família. Muitos são solteiros e os poucos que são casados deixaram esposa e filhos em seu país de origem. A maioria tem o wolof como língua materna e falam outras línguas, como o francês, o árabe, o pular, o soninquê ou o manlinka. Eles seguem as tradições islâmicas e frequentemente promovem atividades relacionadas a hábitos religiosos, como festas e eventos abertos à comunidade. Uma das festas é a celebração do Grande Magal de Touba, cuja data é determinada pelo calendário islâmico. Esses eventos permitem que o grupo de senegaleses se reúna para fazer orações e reviver algumas tradições da cultura de seu país.

O olhar brasileiro acerca desses imigrantes são diversos. Tedesco e Gzybovski (2011) destacam que os senegaleses foram caracterizados, por empresários brasileiros, como trabalhadores honestos, disciplinados e unidos. Lemos e Pereira (2018) salientam, por outro lado, que mesmo quando trabalham de forma regular, atuam como vendedores ambulantes em períodos de folga. Os senegaleses, em entrevistas realizadas para esta pesquisa, afirmam que têm vocação para exercer tal atividade.

Embora sua remuneração seja baixa, a maior parte desse grupo de imigrantes tem fonte de renda e alguns, regularmente, enviam auxílio financeiro para os familiares que permaneceram no Senegal.

Os senegaleses que habitam a região Sul reportam ter certo desconforto e insegurança em relação à permanência no país. Estão sempre atentos e preocupados com a regularização de documentação que garanta suas permanências no Brasil. Estão, consequentemente, em contato com a Polícia Federal e as Defensorias Públicas, que informam e esclarecem questões relacionadas aos trâmites burocráticos acerca do processo de regularização de imigrantes no país. Esses contatos são mais tranquilos quando utilizam com mais fluência a língua local. $\mathrm{O}$ uso da língua portuguesa, nesse tipo de situação, atua de modo favorável, promovendo uma maior independência do sujeito imigrante e atenuando preconceitos. 
Com o objetivo de permanecer no país, os imigrantes solicitam o estatuto de refugiado. O Gráfico 2 apresenta dados referentes ao número desse tipo de solicitação por indivíduos de diferentes nacionalidades.

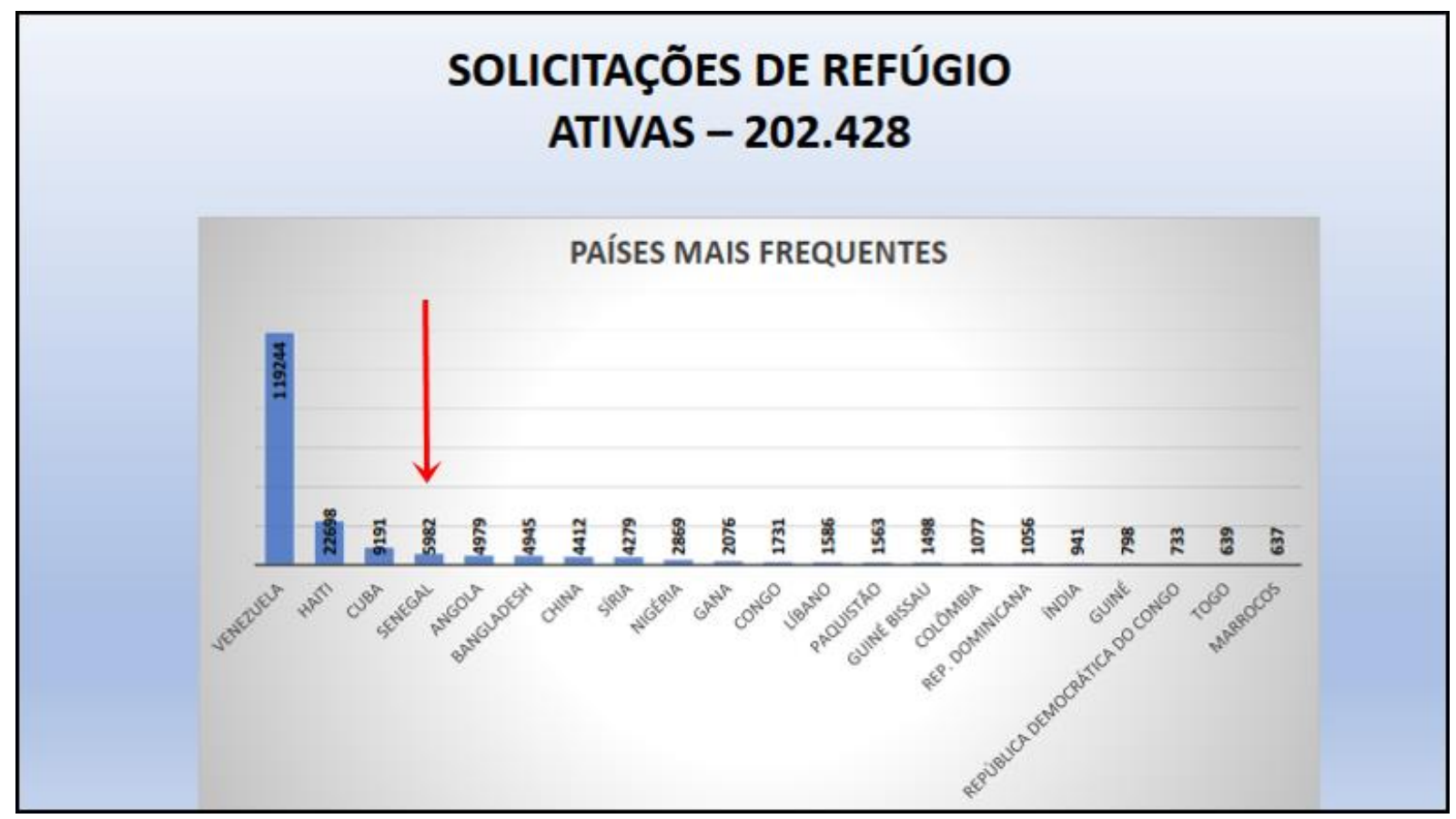

Gráfico 2 - Solicitações de refúgio ativas até setembro/2019. Adaptado da Polícia Federal.

Embora as solicitações de refúgio realizadas por senegaleses estejam entre as mais frequentes, como pode ser visto no Gráfico 2, a maior parte desses imigrantes não se enquadra no perfil de refugiado. De fato, esses imigrantes partem do Senegal de modo voluntário, em busca de trabalho em países que possam abrigá-los, o que os caracteriza como imigrantes econômicos. Desse modo, os senegaleses raramente têm direito à condição de refugiado, o que gera o indeferimento de $99 \%$ desse tipo de solicitação.

Na seção seguinte, pretende-se abordar aspectos linguísticos relacionados ao processo de aquisição do português brasileiro por imigrantes senegaleses.

\section{A aquisição do português brasileiro por imigrantes senegaleses}

Como destacado, adquirir a língua do país de acolhimento é um trunfo. De fato, dominá-la pode representar um ganho, um passo determinante em direção à inserção no país de chegada. Na maior parte dos casos, os senegaleses partem do Senegal sem terem iniciado a aprendizagem da língua falada do país para o qual pretendem emigrar e, no caso de virem para o Brasil, não encontram uma estrutura de acolhida que garanta a aprendizagem do PB. O país possui precárias leis e políticas públicas visando ao acolhimento e à integração da 
população de imigrantes e de refugiados. Algumas universidades federais brasileiras promovem cursos de língua portuguesa para estrangeiros, mas essas iniciativas não fazem parte de uma agenda governamental e, por esse motivo, podem ou não atingir o seu público alvo. Além disso, quando têm a chance de habitarem centros em que cursos gratuitos dessa natureza são ofertados, nem sempre os horários coincidem com os que são mais disponíveis para os imigrantes. Logo, frequentemente, acabam adquirindo o português por meio de imersão.

"É consensual que uma das maiores necessidades e dificuldades encontradas pelos imigrantes e refugiados está relacionada ao domínio do idioma do país de acolhimento, sendo o acesso à Língua Portuguesa como Língua de Acolhimento um desafio (...)" (HARTWIG, 2017, p.5). Assim, como trabalhadores do comércio informal, os senegaleses dependem muito do uso do PB para vender suas mercadorias. Para negociar, necessitam entrar em contato com os transeuntes - seus potenciais compradores - e interagir para informar sobre os artigos que oferecem. Precisam, também, dialogar com fiscais da prefeitura, que podem recolher mercadorias a serem vendidas sem autorização. Resistir à apreensão dessas mesmas mercadorias necessita um uso mais preciso da língua portuguesa. Quando isso ocorre, outros agentes participam da comunicação: a presença da polícia pode ser solicitada para intervir, por exemplo. Como trabalhadores do mercado formal, o domínio da língua é essencial, pois dele depende o "acesso a atividades profissionais específicas, a progressão na carreira ou o alargamento do campo de possibilidades profissionais (...), enquadrando-se no domínio de projetos pessoais de mobilidade social ascendente" (HARTWIG, 2017, p.5). Diante desse contexto, o precário emprego do $\mathrm{PB}$ pouco contribui em relação ao direito à cidadania e ao acesso a espaços sociais diversificados.

Estabelecendo contato informal com os senegaleses, assistindo a matérias televisivas sobre esses imigrantes e realizando entrevistas para a realização desta pesquisa, foi possível perceber que alguns sons específicos do português brasileiro não são por eles efetuados de modo a garantir uma comunicação sem entraves. É o que ocorre com os sons fricativos. Por exemplo, a palavra jogo, que é produzida comumente pelos brasileiros como ['zogu], pode ser articulada pelos senegaleses como ['zogu] ou ['Jogu]. A palavra chefe, produzida por brasileiros como [' $\left.\int \varepsilon f i\right]$, pode ser pronunciada como ['sefi] pelos mesmos imigrantes. As substituições supracitadas compreendem, no caso de jogo, em dificuldades concernentes (i) ao ponto de articulação. Dessa maneira, no lugar de realizarem o segmento com uma constrição na região pós-alveolar com a parte anterior da língua - e com a vibração das pregas vocais -, para produzir o segmento [3], mantêm a sonoridade, mas efetuam a constrição na região dos 
alvéolos e produzem [z] ou (ii) mantêm a constrição na região pós-alveolar, mas o fazem sem que as pregas vocais vibrem e, consequentemente, produzem o segmento [ $\left.\int\right]$. No que diz respeito a chefe, o problema concerne ao ponto de articulação. Assim, em vez de a constrição ocorrer em direção à região pós-alveolar, realiza-se nos alvéolos.

Como já mencionado anteriormente, a maioria dos imigrantes vindos do Senegal que moram no Brasil tem o wolof como língua materna. Alguns falam francês, usam o árabe para orações - que são realizadas cinco vezes ao longo do dia - e, a depender de sua região de origem, compreendem outros idiomas nacionais, como o pular e o soninquê. Acredita-se que a aquisição do PB pode sofrer influência dessas línguas, já presentes no repertório desses imigrantes, o que pode, em parte, explicar as produções idiossincráticas dos sons fricativos supra citados.

$\mathrm{Na}$ seção seguinte, pretende-se discorrer acerca de aspectos linguísticos mais específicos quanto às consoantes fricativas alveolares $[\mathrm{s}, \mathrm{z}]$ e alveopalatais $\left[\int, 3\right]$ do português brasileiro.

\section{Aspectos articulatórios da produção dos sons fricativos alveolares e alveolopalatais do português brasileiro}

Diferentes estudos relacionados à classe de consoantes fricativas alveolares e alvelopalatais já foram realizados (LADEFOGEP; MADDIESON, 1996; JESUS, 2000; JONGMAN et al., 2000; HAUPT, 2007; SAMCZUK; GAMA, 2004), no entanto, ainda há muito a ser estudado a respeito da aquisição dessa classe de sons.

A produção dos sons fricativos é gerada, como observamos, a partir de uma constrição em algum ponto do trato vocal. Essa constrição, que ocorre devido à aproximação da língua em direção ao palato, origina uma turbulência, que ocasiona o ruído fricativo.

A Figura 1 contém imagens estilizadas do trato vocal (em forma de tubo), representando as consoantes (a) fricativa alveolar e (b) fricativa alveopalatal:

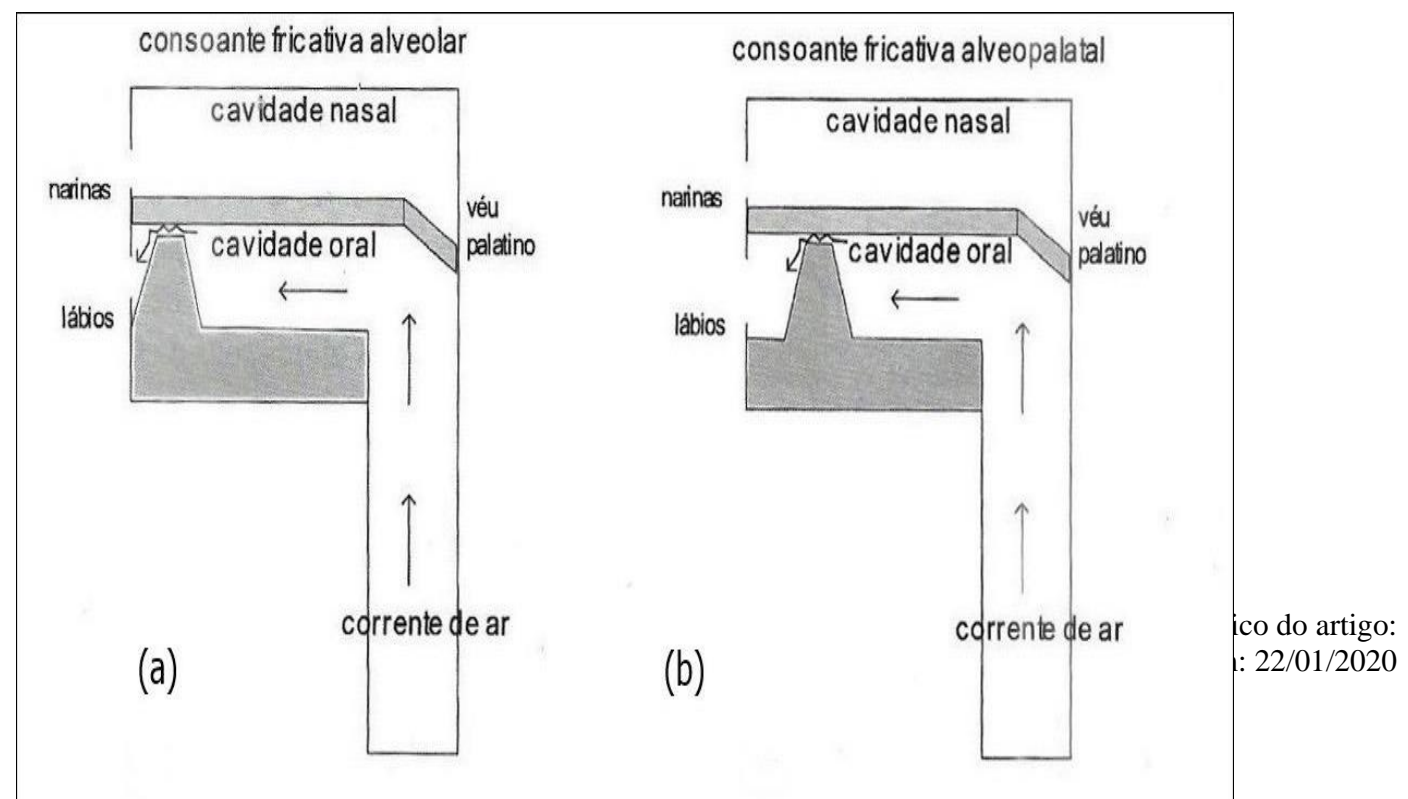


Figura 2 - Consoantes fricativas (a) alveolar e (b) alveopalatal (Adaptado de SILVA et al., 2019).

É possível observar que as fricativas (a) alveolares [s, z] são realizadas a partir de um estreitamento formado pela aproximação entre a ponta da língua e a região dos alvéolos. Dessa maneira, "as partículas de ar se juntam e se separam causando fricção. A fricção provoca um ruído causado pela turbulência da passagem da corrente de ar pela parte estreita do trato vocal" (SILVA et al., 2019, p.169-170).

Não há passagem do ar advindo dos pulmões para a cavidade nasal, pois o véu palatino encontra-se elevado, o que restringe a passagem de ar à cavidade oral. Na Figura 1, também é possível visualizar uma linha em zigue-zague, formando uma seta. Tal recurso indica o local em que há uma fricção. Comparadas as fricativas alveolopalatais às fricativas alveolares, estas são articuladas em uma região um pouco mais anterior do trato vocal. As consoantes alveolopalatais $\left[\int, 3\right]$ são produzidas por meio de uma constrição com a parte anterior da língua, que "toca ou se dirige para a região medial do palato duro" (SEARA et al, 2011, p.50). Nota-se, igualmente, que os segmentos [s, $\left.\int\right]$ são sons desvozeados ou surdos (ocorrem sem que as pregas vocais vibrem) e que $[\mathrm{z}, 3]$ são vozeados ou sonoros (neste caso, as pregas vocais vibram).

Para brasileiros adultos, cuja aquisição do PB ocorreu sem entraves, a articulação dessas consoantes ocorre de modo preciso e automático. Por que razão os imigrantes senegaleses tendem a produzi-las de modo a alterar o local de sua articulação ou o seu vozeamento?

Comparemos, no próximo item, as consoantes do PB e do wolof par tentar encontrar algum elemento de resposta a essa questão.

\section{Consoantes do PB e do wolof, língua materna dos informantes}

O Quadro 1 contém as consoantes do português brasileiro. Encontram-se em destaque as consoantes fricativas vozeadas $[\mathrm{z}, \mathrm{z}]$ e as consoantes fricativas desvozeadas $\left[\mathrm{s}, \int\right]$. Logo a seguir, o Quadro 2 contém as consoantes do wolof. Em destaque, a única consoante alveolar desse sistema linguístico. Ademais, observa-se a inexistência de consoantes palatais. O wolof é, pois, uma língua que contém um único segmento fricativo entre os alvéolos e a região velar. No PB, encontram-se oito segmentos nessas regiões do palato. A comparação entre as consoantes fricativas de ambas as línguas fornece uma explicação - parcial - para as produções peculiares dos senegaleses em língua portuguesa. 
RELACult - Revista Latino-Americana de Estudos em Cultura e Sociedade

Revista Latinoamericana de Estudios en Cultura y Sociedad | Latin American Journal of Studies in Culture and Society V. 06, n⿳0 01, jan-abr., 2020, artigo n' 1765 | claec.org/relacult | e-ISSN: 2525-7870

\begin{tabular}{|c|c|c|c|c|c|c|c|c|}
\hline Artic & & Bilabial & Labiodental & Dental & Alveopalatal & Palatal & Velar & Glotal \\
\hline Maneira & Lugar & Dilaviai & Laviouental & Alveolar & AIVE & ratatai & Vetiar & Givian \\
\hline Oclusiva & $\begin{array}{l}\text { desv } \\
\text { voz }\end{array}$ & $\begin{array}{l}\mathrm{p} \\
\mathrm{b}\end{array}$ & & $\begin{array}{l}\mathrm{t} \\
\mathrm{d}\end{array}$ & & & $\begin{array}{l}\mathrm{k} \\
\mathrm{g}\end{array}$ & \\
\hline Africada & $\begin{array}{l}\text { desv } \\
\text { voz }\end{array}$ & & & & $d \int_{3}$ & & & \\
\hline Fricativa & $\begin{array}{l}\text { desv } \\
\text { voz }\end{array}$ & & $\begin{array}{l}f \\
v\end{array}$ & $\begin{array}{l}\mathrm{s} \\
\mathrm{z}\end{array}$ & $\int_{3}$ & & $\begin{array}{l}X \\
\gamma\end{array}$ & $\begin{array}{l}h \\
6\end{array}$ \\
\hline Nasal & voz & $\mathrm{m}$ & & $n$ & & $\mathrm{n} \tilde{\mathrm{y}}$ & & \\
\hline Tepe & voz & & & f & & & & \\
\hline Vibrante & voz & & & $\check{\mathrm{r}}$ & & & & \\
\hline Retroflexa & voz & & & $\downarrow$ & & & & \\
\hline Lateral & voz & & & $1 t$ & & $\mathrm{~K}^{\mathrm{j}}$ & & \\
\hline
\end{tabular}

Quadro 1 - Consoantes do português brasileiro (CRISTÓFARO SILVA, 2009).

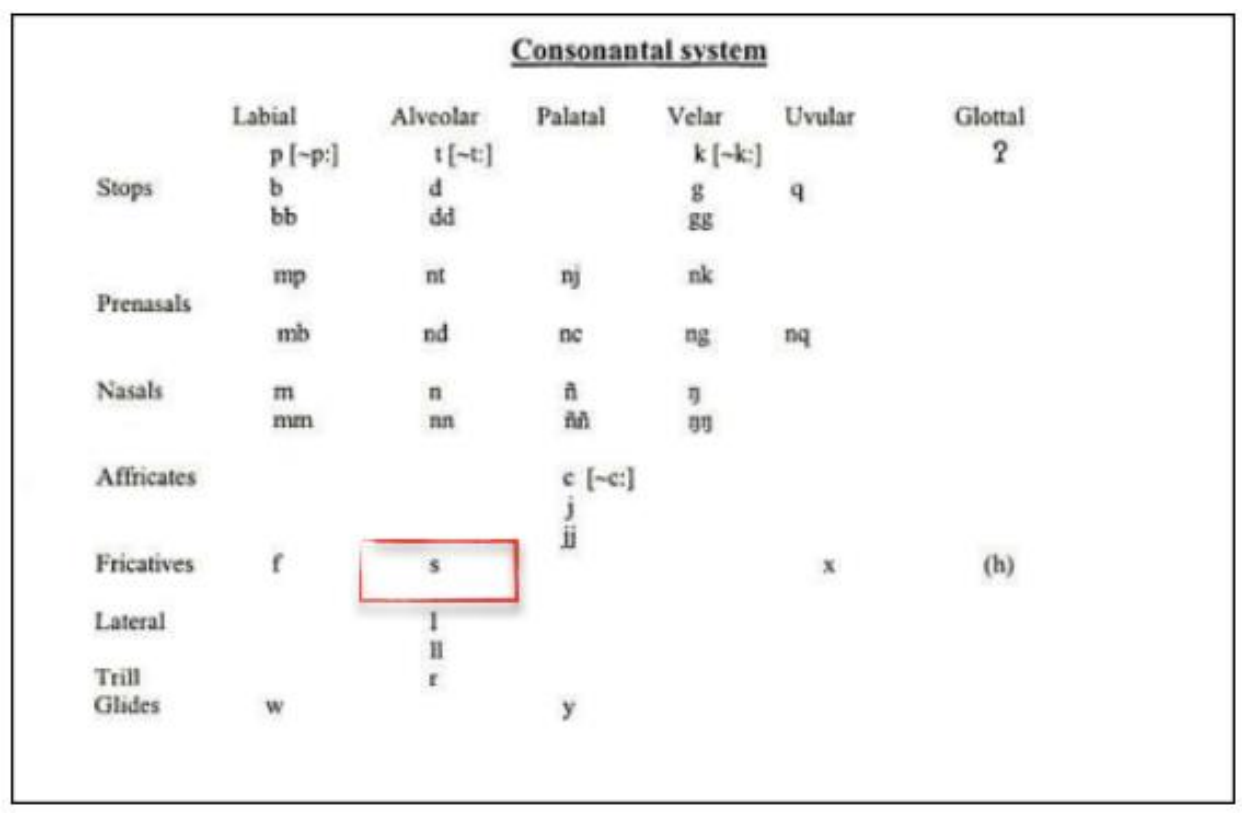

Quadro 2-Consoantes do wolof (NGOM, 2003).

De fato, a língua wolof pode auxiliar a explicar o fato de a palavra [' $\left.\int \varepsilon f i\right]$ ser pronunciada como ['sefi]: na aquisição do PB (L2) por senegaleses falantes de wolof (L1), sons fricativos produzidos entre os alvéolos e o véu do palato tenderiam a ser abrigados na única categoria existente nessas regiões do trato vocal em wolof. 
Na Figura 2, propõe-se uma representação da assimilação das categorias /s/ e / $/$ do PB por falantes de wolof, que possuem somente a categoria $/ \mathrm{s} /$.

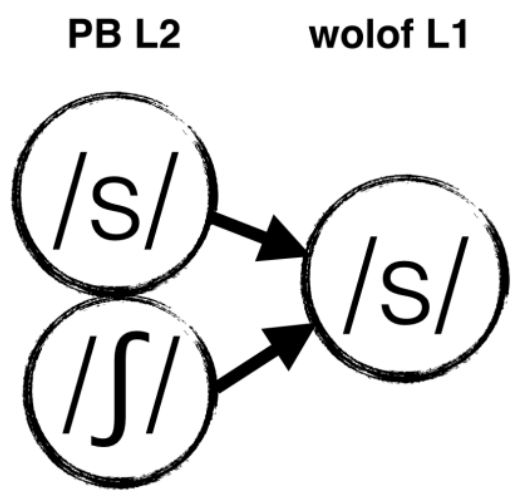

Figura 3 - Assimilação de sons fricativos do PB L2 por locutores de wolof L1

É o que ocorre no caso de chefe (produzido como ['sefi]). Esse processo reduz, assim, a uma as consoantes fricativas desvozeadas do PB. Outros pontos, no entanto, são passíveis de atenção: na produção de jogo, os senegaleses produzem['zogu] ou ['Jogu]. Como explicar tal fato?

A primeira possibilidade pode estar associada aos outros idiomas falados pelos senegaleses. A língua francesa, por exemplo, empregada pelos informantes desta pesquisa, possui as consoantes $\left[\mathrm{z}, \int\right]$. Os informantes, consequentemente, produzem esses sons quando falam francês. Eles estariam, então, transferindo esses sons do francês para o PB de modo não apropriado. Porém, o francês também possui a consoante [3]. Por que, então, não a transferem para o $\mathrm{PB}$, o que tornaria adequada a pronúncia desses informantes nessa língua?

A segunda explicação concerne a ideia de que os usos inadequados dos sons fricativos revelariam hipóteses dos aprendizes senegaleses em relação ao funcionamento do PB. As produções dos senegaleses mostram que um mesmo informante produz o mesmo item lexical ora de um modo, ora de outro. É como se estivesse testando o emprego desses segmentos. Assim, as consoantes $\left[\mathrm{z}, \int\right]$ alternariam, na produção de jogo, por conta de uma possível insatisfação em relação ao seu emprego. Possivelmente o locutor perceba que não é nenhum desses dois sons a forma adequada. Para que possa, então, produzir jogo de modo apropriado, o aprendiz precisa descartar esses dois usos ou se apoiar em características de cada um desses sons a fim de produzir, enfim, a consoante [3]. De fato, [J] pode se tornar [3] se as pregas vocais vibrarem; [z] pode se tornar [3] se a língua se deslocar um pouco em direção ao palato. 
A tarefa não é trivial, pois $\left[\mathrm{z}, \int, 3\right]$ não são sons pertencentes ao wolof e são consoantes que diferem de modo sutil entre elas.

\section{Considerações finais}

Considerando os aspectos até aqui abordados, observa-se que os imigrantes senegaleses, em seu cotidiano no Brasil, lidam com múltiplas adversidades, que envolvem uma nova língua, novos costumes, hábitos e uma cultura diferente. Movidos pelo desejo de enviarem auxílio aos familiares e conseguirem uma vida digna no país de acolhimento, trabalham, em certos casos, em condições precárias, com baixa remuneração salarial. Os trâmites burocráticos que envolvem a permanência desses imigrantes no território brasileiro também geram incertezas a suas rotinas. Com o auxílio da Polícia Federal e Defensorias Públicas, tentam sanar as dúvidas referentes à documentação e manter a estadia no Brasil para dar continuidade às atividades laborais e seguir em busca de melhores condições para o futuro.

Ainda sobre os desafios aqui enfrentados, os imigrantes senegaleses reportam que a aquisição do português brasileiro não é fácil e que, por vezes, é trabalhoso estabelecer uma comunicação com os brasileiros. Em relação à pronúncia, percebe-se que têm dificuldades na produção de certos sons do português. Destacou-se, neste artigo, o caso das fricativas alveolares e alveolopalatais do PB.

Faz-se necessário destacar a importância de trabalhar as especificidades que envolvem a aquisição de uma língua estrangeira, pois "comunicar com êxito depende muito de uma boa pronúncia e (...) uma pronúncia pouco cuidada em língua estrangeira pode levar a incompreensões e a mal-entendidos durante a comunicação interpessoal, quando não origina sua ruptura" (BRUM-DE-PAULA e FERREIRA-GONÇALVES, no prelo).

A pesquisa parcialmente apresentada neste artigo está em desenvolvimento, visa a compreender a aquisição das consoantes fricativas pelos informantes senegaleses a partir de entrevistas, coletas de dados e análises acústicas do material linguístico coletado. Será, então, possível encontrar elementos de resposta às hipóteses levantadas para contribuir com uma melhor descrição do português falado por esse grupo e identificar o modo como os senegaleses adquirem esse sistema linguístico em situação de imersão, principalmente.

\section{Referências}

BARBOSA, Plínio A.; MADUREIRA, Sandra. Manual de Fonética acústica experimental: aplicações a dados do português. São Paulo: Cortez, 2015. 
BRUM-DE-PAULA, M. R.; FERREIRA-GONÇALVES, G. O sistema vocálico do Português Brasileiro, 2020 (no prelo).

DIOP, Momar. Place de la langue <<wolof〉> dans le paysage linguistique du Sénégal : le cas de Dakar. L'aménagement linguistique et didactique de la coexistence du français et des langues nationales au Sénegal, 1998, DiversCité Langues, vol. III.

EPIGEN-Brasil. Disponível em: <https://epigen.grude.ufmg.br> Acesso em 15 dez 2019.

FOURIER, Joel.; LAND, Victoria Van der. Focus Senegal. In: HUMMEL, Diana.; DOEVENSPECK, Martin.; SAMIMI, Cyrus. Climate change, environment and migration in the Sahel - Selected issues with a focus on Senegal and Mali. Micle work paper n. 1. Frankfurt/Main. 2012.

HARTWIG, F. B. A importância do português como língua de acolhimento na integração de alunos imigrantes e refugiados no Instituto Federal de Brasília - IFB. Revista da UIIPS, vol. 5, $\mathrm{n}^{\circ} 3,2017$.

HAUPT, Carine. As fricativas [s], [z], [J] e [3] do português brasileiro. Estudos Linguísticos XXXVI(1), 2007.

JONGMAN, Allard.; WAYLAND, Ratree.; WONG, Serena. Acoustic characteristics of English fricatives. The Journal of the Acoustical Society of America. v. 108, n. 3, 2000.

KENT, Ray D., READ, Charles. Análise acústica da fala. 1ª ed. São Paulo: Cortez, 2015.

LEMOS, Luciane Oliveira. PEREIRA, Vilmar Alves. Senegaleses em Rio Grande - RS: diálogo intercultural no além-mar. Revista Latino-Americana de Estudos de Cultura e Sociedade. v. 4, n. 668, 2018.

LOSI, Clara, Lu Deu Waxu, Ce média qui veut rendre au wolof ses lettres de noblesse. Carnet du Sénégal, 2019.

NDIAYA, Cisse.; LV, Kangjuan. Role of industrialization on economic growth: the experience of Senegal (1960-2017). American Journal of Industrial and Business Management, n. 8, 2018.

NEALON, Cory. New mapping technique can help fight extreme poverty. University at Buffalo, 2017. Disponível em: <http://www.buffalo.edu/news/releases/2017/12/006.html>. Acesso em: $11 \mathrm{dez} 2019$.

NGOM, Fallou. A sociolinguistic profile of senegalese speech community. Studies in the Linguistic Sciences. v. 29, n. 1, 1999.

RODRIGUES JUNIOR, Luzivaldo de Souza. Polícia Federal. Disponível em: <http://www.pf.gov.br/servicos-pf/imigracao/Apresentao_setembro_2019_VF.pdf/view> Acesso em: $13 \mathrm{dez} 2019$. 
SEARA, I. C.; NUNES, V. G.; LAZZAROTTO-VOLCÃO, C. Fonética e fonologia do português brasileiro. Florianópolis: LLV/CCE/UFSC, 2011.

SILVA, Diego Barbosa da. Política linguística na África: do passado colonial ao futuro global. Revista África e Africanidades. n. 10, 2010.

SILVA, Cristófaro Thaís. Et al. Fonética Acústica: os sons do português brasileiro. São Paulo: Contexto, 2019.

TEDESCO, João Carlos; GRZYBOVSKI, Denize. Senegaleses no norte do Rio Grande do Sul: integração, cultura, trabalho e dinâmica migratória internacional. Revista Espaço Pedagógico, v. 18, n. 2, Passo Fundo, 2011.

THE WORLD FACT BOOK. Senegal. Disponível em: < https://www.cia.gov/library/publications/the-world-factbook/geos/sg.html>. Acesso em: 12 dez 2019.

UEBEL, Roberto Rodolfo. Aspectos gerais da dinâmica imigratória no Brasil no século XXI. Migrações Internacionais, Refúgio e Políticas, São Paulo, 2016.

Roberto Rodolfo. Panorama e perfil da imigração senegalesa no Rio Grande do Sul no início do século XXI. Boletim Geográfico do Rio Grande do Sul, Porto Alegre, n. 28, 2016.

VASCONCELLOS, Manuela. Comunidade senegalesa em Santa Maria realiza celebração em memória de líder espiritual. Prefeitura Municipal de Santa Maria, 2019. Disponível em: $<$ https://www.santamaria.rs.gov.br/noticias/19764-comunidade-senegalesa-em-santa-mariarealiza-celebracao-em-memoria-a-lider-espiritual>. Acesso em: 13 dez 2019.

VIDIGAL, Lucas. Senegaleses que pediram refúgio no Brasil terão novo procedimento para obter autorização de residência. G1, 2019. Disponível em: <https://g1.globo.com/mundo/noticia/2019/12/06/senegaleses-que-pediram-refugio-no-brasilterao-novo-procedimento-para-obter-autorizacao-de-residencia.ghtml> Acesso em: $11 \mathrm{dez}$ 2019.

WENCZENOVICZ, Thaís Janaina. Imigrantes senegaleses no Brasil e Direitos Humanos: vivências e oralidade. Revista África(s). v. 3, n. 5, 2016. 